\title{
CHAVE DE CLASSIFICAÇÃO PARA IDENTIFICAÇÃO DE VEGETAÇÃO EM FOTOGRAFIAS PANCROMÁTICAS COLORIDAS e INFRAVERMELHAS COLORIDAS ***
}

\author{
Eng..$^{\circ}$ Agr..$^{\circ}$ Gilberto J. Garcia *** \\ ENG. ${ }^{\circ}$ AGr. ${ }^{\circ}$ Delmar A. B. Marchetti
}

\section{RESUMO}

Chave de classificação para identificação de vegetação em fotografias pancromáticas, coloridas e infravermelhas coloridas.

$\mathrm{O}$ trabalho em questão objetivou a elaboração de uma chave de classificação para identificação de diferentes tipos de vegetação, natural e de culturas.

Os estudos basearam-se $\mathrm{cm}$ fotografias pancromáticas, coloridas e infravermelhas coloridas de uma área teste localizada no município de Campinas - SP.

A cobertura fotográfica denominada Missão 96 resultou da colaboração científica entre INPE - Instituto de Pesquisas Espaciais, NASA - National Aeronautics and Space Administration e IAC - Instituto Agronômico do Estado de São Paulo.

No estudo, a vegetação foi dividida em dois grupos principais: natural e culturas. A vegetação natural foi subdividida em mata, cerrado, campo limpo e campo sujo, enquanto que as culturas subdivididas em café, pomar cítrico, pomar não cítrico, eucalipto jovem, eucalipto de dois ou mais cortes, pastagens e culturas anuais.

Os valores foram obtidos em amostras circulares de $10 \mathrm{~km}^{2}$ inteiramente casualizadas. Os resultados obtidos foram utilizados para avaliar a eficiência da chave de classificação e de cada tipo de fotografia.

Para as condições estudadas, obteve-se as conclusões principais : a) Para a escala utilizada, a chave de classificação proposta apresentou uma boa porcentagem de eficiência, podendo ser recomendada para futuros trabalhos.

b) No estudo da vegetação natural, os três tipos de fotografias revelaram a mesma eficiência no que se refere à porcentagem de itens identificados corretamente.

c) No estudo das culturas, a fotografia colorida e a infravermelha colorida, forneceram resultados semelhantes, superiores no entanto à fotografia pancromática, quanto à porcentagem de itens identificados corretamente.

* Enviado para publicação em 14/12/1976

* Trabalho apresentado no VI Congresso Nacional de Engenharia Agrícola - 1976 Centro Nacional de Engenharia Agrícola (Fazenda Ipanema) - SP

** Dept. ${ }^{\circ}$ de Engenharia Rural da Faculdade de Ciências Médicas e Biológicas de Botucatu - SP UNES

*** Depat.o de Engenharia Rural da Escola Superior de Agricultura "Luiz de Queiroz" - USP Piracicaba - SP 


\section{INTRODUÇÃO}

O presente trabalho objetivou a elaboração de uma chave de classificação para identificação de diferentes tipos de vegetação, natural e de culturas.

Conforme relata SPURR ${ }^{(16)}$, a fotointerpretação da vegetação começou quando se tornou necessário o levantamento de áreas de difícil acesso. Ainda segundo o mesmo autor, a fotointerpretação da vegetação exige basicamente o conhecimento das espécies mais comuns da flora, sua representação em fotografias aéreas e os tipos de plantas que geralmente se associam.

No que concerne às características da vegetação, GATES(7), comenta que a aparência das plantas e das superfícies vegetais dependem de sua interação com a radiação, sendo influenciada pela geometria das folhas, morfologia, fisiologia, composição química, solo e clima. O referido autor relata ainda, que na região do visível as folhas das diferentes espécies apresentam uma baixa refletividade não diferenciada. Esta refletividade cresce com o aumento do comprimento de onda, apresentando já na faixa pertencente ao infravermelho uma sensível distinção. Esta distinção na região infravermelha do espectro eletromagnético deve-se à quantidade de clorofila. Com exceção do vermelho, o verde, o amarelo e o infravermelho são refletidos do mesófilo, emergindo da folha e conferindo-lhe a cor verde. A reflexão no verde é geralmente baixa (10 a 20\%), mas devido à grande sensibilidade do olho humano para o verde, vê-se a luz neste comprimento de onda com grande distinção.

Torna-se óbvio portanto, que a utilização de diferentes tipos de filmes na fotointerpretação da vegetação acrescena novas possibilidades ao analista.

No estudo da vegetação, a primeira providência é a sua divisão em classes, sendo que o nível mais genérico seria: a) vegetação natural e b) culturas, conforme citação de BRADSHAW ${ }^{(2)}$.

Quanto à vegetação natural, MOESSNER ${ }^{(9)}$, propõe que uma classificação seja: a) tipo de vegetação com base nas espécies; b) posição da vegetação, com base na topografia e condições de solo; c) altura da vegetação, baseada no diâmetro e na altura das árvores e d) condições de vegetação, em função do tratamento anteriormente recebido. Cada um destes itens pode ser desdobrado, constituindo-se em classificações tanto quanto mais próximas da realidade da região.

Qualquer que seja o tipo de divisão adotado, o importante é a elaboração de chaves de classificação, e, conforme assinalam SIMONTACCHI et alii(15), estas pode mser de seleção ou de eliminação. A de seleção seria montada de tal maneira que o fotointérprete seleciona o 
exemplo correspondente a imagem que estivesse tentando identificar. A de eliminação é montada de tal modo que o fotointérprete acompanha uma seqüência pré-esabelecida, eliminando todos os itens, com exceção daquele que se deseja identificar.

Quanto aos recursos disponíveis para facilitar o reconhecimento: escala, estação do ano e tipo de filme e filtro são variáveis mais acessíveis. Conforme comentam BRADSHAW (2), DAMMES ${ }^{(5)}$, POPE (13), BEC$\mathrm{KING}^{(1)}$ e DUTTON ${ }^{(6)}$, quanto maior a escala mais correta é a identificação da vegetação e espécies vegetais. Relatam ainda que a fotografia infravermelha é melhor que a colorida, e esta melhor que a pancromática. Quanto à estação do ano, SCHREUDER(14), assinala que para as florestas tropicais as épocas mais adequadas para a tomada de fotografias seriam primavera e outono, quando distinção entre as folhagens das diferentes espécies é mais evidente, embora muito inferior às diferenças que ocorrem na floresta temperada no verão e no inverno.

\section{MATERIAIS E MÉTODOS}

\section{1 - Descrição da região estudada}

Os estudos basearam-se em fotografias pancromáticas coloridas e infravermelhas coloridas de uma área teste localizada no município de Campinas - SP.

Tal tipo de cobertura fotográfica, denominada MISSÃO 96, resultou da colaboração científica entre INPE - Instituto de Pesquisas Espaciais, NASA - National Aeronautics and Space Administration e IAC Instituto Agronômico do Estado de São Paulo.

A área teste está localizada entre as latitudes (Sul) de $22^{\circ} 35^{\prime}$ e $22^{\circ} 50^{\prime}$ e longitudes (Oeste) de $47^{\circ} 05^{\prime}$ e $47^{\circ} 20^{\prime}$.

CAMARGO $^{(3)}$ relata que o clima da região é do tipo tropical de altitude, com a temperatura média do mês mais quente igual a $22,8^{\circ} \mathrm{C}$ e a do mês mais frio de $16,6^{\circ} \mathrm{C}$, sendo menor que $30 \mathrm{~mm}$ a precipitação do mês mais seco, de um total de $1388 \mathrm{~mm}$ durante o ano.

Pela COMISSÃO DE SOLOS ${ }^{(1)}$ e segundo informações verbais da Secção de Pedologia do Instituto Agronômico do Estado de São Paulo, a área apresenta na sua quase totalidade solos da categoria Latossolo. O relêvo da região é normal, suavemente ondulado, com declives mistos, médios a longos e irregulares, com declivedade máxima de $8 \%$.

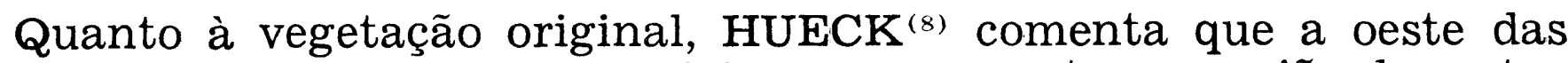
montanhas costeiras do Brasil, iniciava-se uma extensa região de matas 
que diferia profundamente das matas pluviais de montanhas, tropicais e subtropicais. Até o século XVII elas formavam toda a escala de matas subtropicais perenifólias, com mistura de árvores caducifólias, matas úmidas decíduas até mata semi-áridas que permaneciam desfolhadas de 4-5 meses por ano. A cobertura de matas era interrompida de quando em vez por campos cerrados.

A situação atual da vegetação nativa é bem diferente. Os processos de ocupação devastaram completamente os grandes maciços florestais da região, com exceção de pequenas glebas esparsas.

Freqüentemente o campo limpo é empregado como pastagem natural e é caracterizado por gramíneas rasteiras, aparecendo esporadicamente áreas de capinzeiros mais altos.

O campo sujo, caracteriza-se pela presença de gramíneas típicas da região e de arbustos esparsos ou associados, espalhados por toda a área.

Quanto às culturas da região, as de maior expressão são as anuais. Dentre essas a de maior expressão econômica é a da cana-de-açúcar, aparecendo ainda hortaliças, arroz, milho e algodão. Em terceiro plaro situam-se a soja e o trigo com ocorrências esparsas.

Das culturas consideradas perenes destacam-se o café, pomares cítricos e não cítricos e povoamentos de eucaliptos, em vários estágios de crescimento. Pastagens formadas também aparecem na área.

\section{$2.2-E s t e r e o s c o ́ p i o s$}

Para observação estereotópica dos pares fotográficos, foram utilizados dois tipos de estereoscópios: um de espelhos Wild ST4 e um de bolso Vasconcellos.

\section{3 - Fotografias aéreas}

As fotografias aéreas disponíveis estão na escala 1:15.000 e 1:3.500. A chave de classificação foi elaborada para as fotografias na escala $1: 15.000$, enquanto que as fotgorafias na escala $1: 3.500$, serviram para o controle da fotointerpretação.

\section{4 - Elaboração da chave de classificação}

No estudo da vegetação utilizou-se toda a cobertura fotográfica, o que perfaz uma área aproximada de $60 \mathrm{~km}^{2}$. Para cada tipo de fotografia demarcou-se os diferentes tipos de vegetação, sendo interpretådas estereoscopicamente. 
Com vistas à análise estatística dos resultados, os estudos foram feitos em amostras circulares de $10 \mathrm{~km}^{2}$, convenientemente distribuídos.

Os elementos estudados foram reunidos inicialmente em dois grupos: vegetação natural e terras com cultura. A vegetação natural foi dividida em mata (CA), serrado (CB), campo limpo (CL) e campo sujo (CS), enquanto que as culturas foram divididas em culturas anuais (CN) e culturas perenes: café $(\mathrm{CF})$, pomar cítrico $(\mathrm{PC})$, pomar não cítrico (PN), eucalipto jovem (EJ), eucalipto de $2 .^{\circ}$ corte ou mais (EA) e pastagens (PA).

A chave de classificação empregada foi a de seleção, onde o fotointérprete seleciona o exemplo correspondente à imagem que está tentando identificar através de suas características marcantes.

$\mathrm{Na}$ caracterização da variável cor utilizou-se da carta de MUNSELL ${ }^{(10)}$ para vegetação.

A chave de classificação foi obtida estudando-se intensivamente uma área teste no local, e através de fotografias na escala 1:15.000 e $1: 3.500$, sendo que estas últimas serviram posteriormente para a confirmação do erro ou acerto cometido pelo fotointérprete para cada objeto identificável existente na amostra circular.

O QUADRO 1, apresenta a chave de classificação adequada para os três tipos de fotografias.

Quanto a tubulação dos dados, adotou-se o critério empregado por NORTHROP e JOHNSON ${ }^{(11)}$, através da consignação de pontos. O número de ocorrências identificadas ou não, percentualmente em relação ao número de ocorrências totais, daria a eficiência da chave de classificação para cada tipo de fotografia.

\section{5 - Análise dos resultados}

A chave de classificação foi testada a partir dos resultados obtidos nas amostras circulares, calculando-se uma porcentagem de eficiência.

Aproveitou-se para estudar ainda a porcentagem de eficiência de cada tipo de fotografia, e neste caso adotou-se o delineamento experimental de parcelas inteiramente casualisadas, consistindo de três tratamenos com sete repetições.

Os ratamentos referiram-se aos três tipos de filmes, sendo: Fotografia pancromática; Fotografia colorida e Fotografia infravermelha colorida. As repetições constituíram-se nas amostras circulares de $10 \mathrm{~km}^{2}$.

Os processos estatísticos adotados são os expostos em PIMENTEL GOMES $^{(12)}$. 
QUADRO 1 - Chave de classificação (tipo seleção) para os tipos de vegetação existentes no Município de Campinas

Tipo Características

Mata $(\mathrm{CA})$

Forma irregular; sombras irregularmente distribuidas no dossel, provenientes das espécies dominantes; porte alto; textura grosseira, devido às espécies dominantes; tonalidade escura para o filme pancromático (N3.5/); cor verde escura para o colorido (5.7GY3.6/4.8 + 8.0GY2.2/3.6) e vermelha para o infravermelho colorido (9.3RA.0/9.1 + 9.8R5.4/14.5).

Cerrado $(\mathrm{CP})$

Forma irregular; presença de sombras, porém em menor número e tamanho; porte médio; textura média; tonalidade escura para o filme pancromático (3.3GY5.4/0.1); cor verde escura para o colorido (7.46Y4.2/7.1 + $+5.7 \mathrm{GY3} .6 / 4.8)$ e vermelha para o infravermelho colorido 2.1R6.0/11.1 +2.7 R5.9/6.1).

Campo limpo (CL)

Forma irregular; ausência de sombras provenientes de vegetação; textura fina; tonalidade intermediária para o filme pancromático (6.7Y7.4/0.2); cor verde amarelada para o colorido $(4.8 \mathrm{GY6.0/5.0)}$ e rósea para o infravermelho colorido (2.7R5.9/6.1 + 4.0R4.4/4.8).

Campo sujo (CS)

Forma irregular; presença de sombras provenientes da vegetaçĩo arbustiva escura esparsa; textura fina; tonalidade intermediária para o filme pancromático (6.7Y7.4/0.2); cor verde amarela para o colorido (4.8GY6.0/5.0) e rósea para o infravermelho colorido (2.7R5.9/6.1 + 4.0R4.4/4.8).

Culturas anuais $(\mathrm{CN})$

Formas regulares; ausência de sombras; textura aveludada, muitas vezes marchetada; tonalidade clara e intermediária para o filme pancromático $(6.7 \mathrm{Y} 7.4 / 0.2+3.3 \mathrm{GY} 5.4 / 0.1)$; cor verde amarelada para o coloriclo $(9.2$ Y 7.2/9.2 + 9.5Y7.1/6.5 + 9.0Y7.2/3.9) e vermelha a rósea para o infravermelho (2.1R6.0/11.1 + 2.7R5.9/6.1 + 5.1R2.8/10.1).

Café (CF)

Formas regulares; tallıões pequenos espaçamento característico; ausência de sombras; porte baixo; textura das árvores imperceptível; tonalidarle intermediária para o filme pancromático (6.7Y7.4/0.2); verde escura para o colorido (5.1G3.0/8.1) e vermelha para o infravermelho (7.3R P4.4/11.4). 
Pomar cítrico (PC)

Formas regulares; espaçamento característico; copas pequenas e regulares; presença de sombras; porte alto; textura das árvores imperceptível; tonalidade escura para o filme pancromático (3.3GY5.4/0.1); verde clara para o colorido (9.4Y5.9/6.3) e vermelha para o infravermelho (9.2R3.9/12.1 + $+9.3 \mathrm{R} 5.5 / 9.2)$.

Pomar não cítrico $(\mathrm{PN})$

Formas regulares; espaçamento característico; presença de sombras; copas grandes e arredondadas (mangueira); copas pequenas e irregulares (figo e pessegueiro); textura das árvores imperceptível; tonalidade intermediária a escura para a fotografia pancromática $(6.7 Y 7.4 / 0.2)$; cor verde média a amarelada para o colorido $(9.4 \mathrm{Y} 5.9 / 6.3+7.6 \mathrm{Y} 3.8 / 5.4)$, cor vermelha rósea para o infravermelho $(9.2 \mathrm{R} 3.9 / 12.1-9.3 \mathrm{R} 5.5 / 9.2)$.

Eucalipto jovem (EJ)

Formas regulares; presença de sombras; porte baixo a médio; espaçamento perceptível; textura média; tonalidade escura para o filme pancromático (N3.5/) ; verde médio para o colorido (7.4GY4.2/7.1), e vermelho médio para o infravermelho $(9.2 \mathrm{R} 3.9 / 12.1)$.

Eucalipto de 2 cortes ou mais

Formas regulares; presença de sombras dentro do talhão; porte médio a alto; textura grosseira devido ao crescimento irregular após corte; tonalidade escura para o filme pancromático (N3.5); verde escura para o colorido (7.4GY4.2/7.1), e vermelho para o infravermelho (9.2R3.9/12.1).

Pastagens (PA)

Formas mistas; presença de sombras grandes decorrente de árvore de porte; eventualmente presença de cordões em contorno; textura fina; tonalidade intermediária para o filme pancromático $(6.7 Y 7.4 / 0.2)$; cor verde clara para o coloriclo (5.4GY6.0/8.7), e vermelho claro para o infravermelho (2.1R6.0/11.1). 


\section{RESULTADOS E DISCUSSÃO}

Os resultados obtidos são apresentados nos QUADROS seguintes, enquanto que a FIGURA 1 exemplifica uma amostra da área.

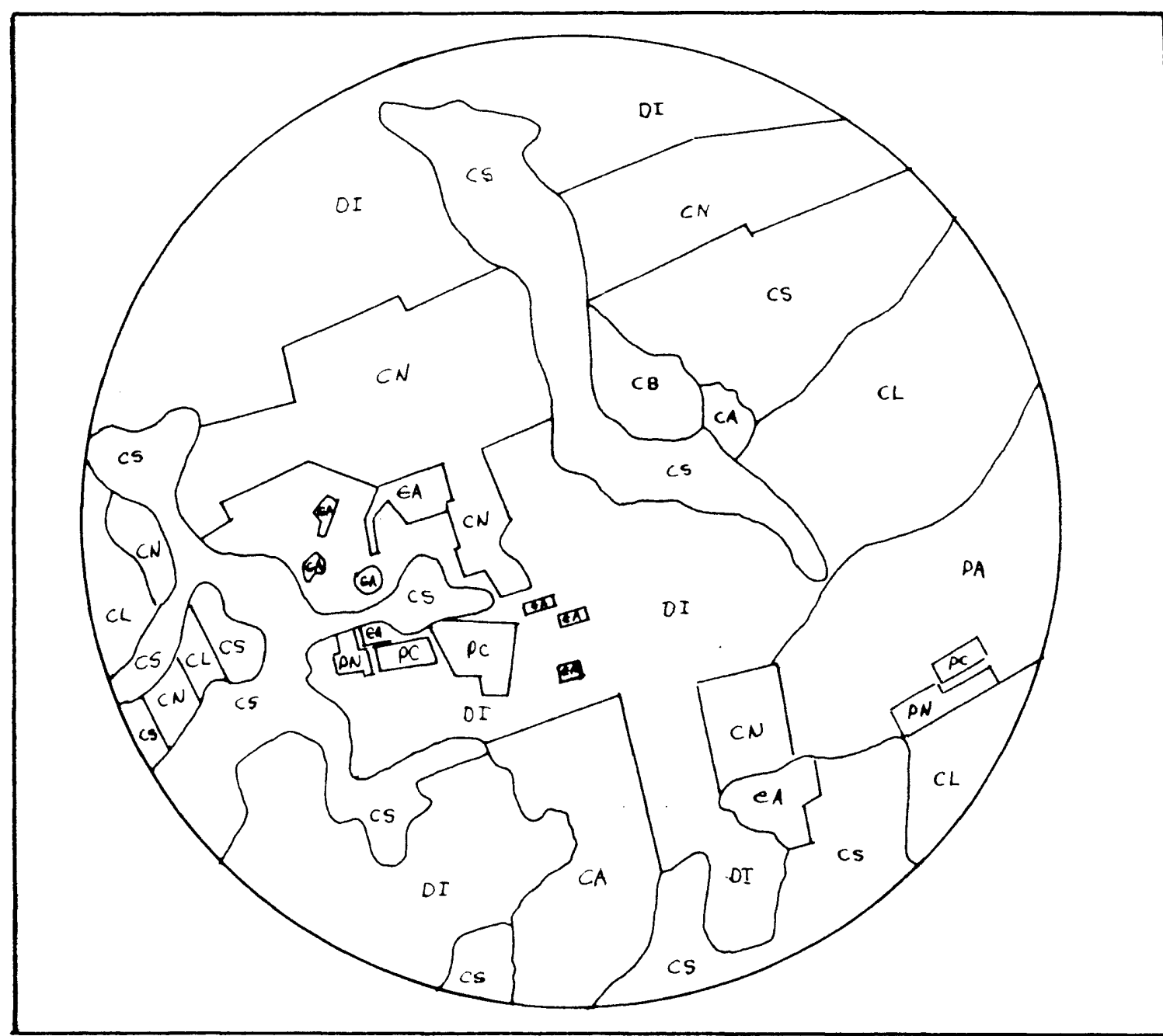

AMOSTRA 1-Esc. aprox. 1:24700

$$
\begin{aligned}
& \text { CA - Moto } \\
& \text { CB - Corrodo } \\
& \text { CL- Compo Limpo } \\
& \text { CS- Compo Sujo }
\end{aligned}
$$

$\mathrm{CN}$ - Culturas anvois

CF- Cofé

PC- Pomar cítrico

EJ-Eucalipto jovem

PN- Pomar nöo citrico

FIGURA I - Divisöo da vegetaçóo para a fotografia pancromótica

O QUADRO 2 mostra as porcentagens de itens identificados na área, podendo-se perceber que a eficiência na identificação da vegetação natural foi de $100 \%$, enquanto que para culturas a eficiência foi de $92,2 \%$.

Analisando-se individualmente cada tipo de fotografia, cujos resultados são apresentados no QUADRO 3, nota-se diferenças nas porcentagens de itens identificados. A análise de variância mostrou que os 
resultados obtidos pelos três tipos de fotografias foram significaivos ao nível de $1 \%$ de probabilidade. A comparação de médias feita pelo teste de Tukey mostrou que a fotografia pancromática e a infravermeìha colorida são estatisticamente diferentes, conforme pode-se observar no QUADRO 4.

QUADRO 2 - Porcentagem de itens identificados na área, através da chave de classificação.

\begin{tabular}{|c|c|c|c|c|c|c|}
\hline \multirow{2}{*}{ Repetições } & \multicolumn{2}{|c|}{ Veg. natural } & \multicolumn{2}{|c|}{ Culturas } & \multicolumn{2}{|c|}{ Total } \\
\hline & Total & Ident. & Total & Ident. & Total & Ident. \\
\hline 1 & 35 & 35 & 91 & 84 & 126 & 119 \\
\hline 2 & 36 & 36 & 122 & 114 & 158 & 150 \\
\hline 3 & 37 & 37 & 72 & 67 & 109 & 104 \\
\hline 4 & 21 & 21 & 54 & 47 & 75 & 68 \\
\hline 5 & 18 & 18 & 45 & 39 & 63 & 57 \\
\hline 6 & 42 & 42 & 108 & 101 & 150 & 143 \\
\hline 7 & 38 & 38 & 112 & 105 & 150 & 143 \\
\hline Médias & 32,4 & 32,4 & 86,3 & 79,6 & 118,7 & 112,0 \\
\hline$\%$ Total & \multicolumn{2}{|c|}{100,00} & \multicolumn{2}{|c|}{92,2} & \multicolumn{2}{|c|}{94,4} \\
\hline
\end{tabular}

QUADRO 3 - Porcentagens de itens identificados para cada tipo de fotografia.

\begin{tabular}{|c|c|c|c|c|c|c|}
\hline \multirow{3}{*}{ Repetições } & \multicolumn{6}{|c|}{ Tipo de fotografia } \\
\hline & \multicolumn{2}{|c|}{ Pancromática } & \multicolumn{2}{|c|}{ Colorida } & \multicolumn{2}{|c|}{ Infravermelha } \\
\hline & Total & Ident. & Total & Ident. & Total & Ident. \\
\hline \multirow[t]{2}{*}{1} & 32 & 29 & 44 & 43 & 50 & 47 \\
\hline & & & 56 & 53 & 61 & 59 \\
\hline 3 & 30 & 28 & 37 & 35 & 42 & 51 \\
\hline 4 & 21 & 18 & 26 & 23 & 28 & 27 \\
\hline 5 & 18 & 16 & 22 & 20 & 23 & 21 \\
\hline 6 & 44 & 40 & 51 & 50 & 55 & 53 \\
\hline 7 & 37 & 34 & 54 & 52 & 59 & 57 \\
\hline Médias & 31,9 & 29,0 & 41,4 & 39,4 & 45,4 & 43,4 \\
\hline$\%$ Total & & 0,9 & & & & \\
\hline
\end{tabular}


QUADRO 4 - Análise de variância e teste de Tukey para a porcentagem de eficiência para cada tipo de fotografia.

\begin{tabular}{ll}
\hline Tipo de fotografia & Médias \\
\hline \hline Pancromática & 90,0 \\
Colorida & 95,2 \\
Infravermelha colorida & 95,6 \\
\hline F. Trat. & $6,20 * *$ \\
DMS 5\% (Tukey) & 4,52 \\
\hline
\end{tabular}

** Valores significativos ao nível de $1 \%$ de probabilidade.

Analisando-se o número total de itens observáveis para cada tipo de fotografia, mostradas no QUADRO 3, pode-se perceber que há uma variação segundo o tipo de fotografia. Assim, a média das sete amostras para a fotografia pancromática foi de 29,0 , para a colorida 39,4 e para a infravermelha colorida 43,4. Desse modo, as fotografias colorida e infravermelha colorida forneceram $26,4 \%$ e $33,2 \%$ mais informações que a fotografia pancromática.

A eficiência da chave de classificação, que pode ser considerada alta, pode ser atribuída em parte à escala das fotografias, e em parte ao tipo de subdivisão efetuada.

A região de Campinas é bastante desenvolvida, e a ocorrência de vegetação nativa é muito pequena, não oferecendo dificuldades a sua distinção. Quanto às culturas anuais, talvez não tenham se constituído em grande problema, por tere msido analisadas como um todo. E provável que com a sua individualização a eficiência média para cada tipo de fotografia fosse mais baixa. No que se refere às culturas permanentes ,os trabalhos foram bastante simplificados, dividindo-se os pomares em cítricos e não cítricos e os povoamentos de eucaliptos, em jovens e de dois ou mais cortes.

Os itens que mais apresentaram erros na identificação foram culturas anuais, pastagem artificial e eucalipto jovem, enquanto que os itens mais facilmente identificados foram mata alta, cerrado baixo e campo sujo. 


\section{CONCLUSÕES}

Para a região estudada os resultados permitem as seguintes conclusões princpiais:

a) Para a escala utilizada, a chave de classificação proposta apresentou uma boa porcentagem de eficiência, podendo ser recomendada para futuros trabalhos.

b) No estudo da vegetação natural, os três tipos de fotografias revelaram a mesma eficiência no que se refere a porcentagem de itens identificados corretamente.

c) No estudo das culturas, a fotografia colorida e a infravermelha colorida forneceram resultados semelhantes, superiores no entanto à fotografia pancromática, quanto a porcentagem de itens identificados corretamente.

\section{SUMMARY}

The objective of the present work is to propose a classification key to the identification of different kinds of vegetation.

The studies were based on panchromatic, color and color inflared photographs of a test area located in the municipality of Campinas - SP.

The photographic flight was carried on by means of a scientific cooperation of INPE - Instituto de Pesquisas Espaciais, NASA - National Aeronautics and Space Administration and IAC - Instituto Agronômico do Estado de São Paulo.

The vegetation was classified in natural and cultivated. The natural vegetation was classified in forest, cerrado, clean field, field with shrubs; and the cultivated in coffee, citrus other orchards mature eucaliptus, immature eucaliptus pasture and annual cultures.

The studies were made in circular samples $10 \mathrm{~km}^{2}$, ramdonly orientated. The obtained data were used to evaluate the efficiency of the classification key and every type of photographs.

For the studied region, the quantitative analysis led he following conclusions:

a) For the utilized scale, the classification key showed a good efficiency, and can be used.

b) The three types of photographs showed the same efficiency in the identification of natural vegetation.

c) The effeciency of color and color infrared photography was similar in the identification of cultivated vegetation, but superior comparatively to panchromatic photography. 


\section{LITERATURA CITADA}

BECKING, R.W. - Forestry Application of Aerial Color Protography. Photogram, Engng. $25: 559-565.1959$.

BRADSHAW, K.E. - Summary of World Progress in Photointerpretation in Natural Resources Inventories. Photogram. Engng., 18:400-411. 1952.

CAMARGO, A.P. de. 1960 - Balanço Hítrico no Estado de São Paulo. Campinas, Instituto agronômico. $20 \mathrm{p}$. (Boletim n. $\left.{ }^{\circ} 116\right)$.

COMISSÃO DE SOLOS DO C.N.E.P.A. 1964 - Levantamento de Reconhecimento dos Solos do Estado de São Paulo. Rio de Janeiro, Centro Nacional de Ensino e Pesquisas Agronômicas. $634 \mathrm{p}$.

DAMMES, H. 1952 - The Use of Aerial Photographs in a Tropical Country (Surinam). Photogram. Engng., $18: 152-158$.

DUTTON, J.A. 1967 - Comparative Photointerpretation from Panchromatic, Color and Color IR Photography. Ohio, 181 p. (Tese M.S. - Ohio State University).

GATES, D.M. 1970 - Physical and Physiological Properties of Plants. In: National Academy of Sciences. Remote Sensing. Washington, p. 224-252.

HUECK, K. $1972 \rightarrow$ As florestas da América do Sul. Brasilia, Ed. Universidade de Brasília. $466 \mathrm{p}$.

MOESSNER, K.E. 1953 - Photo Interpretation in Forest Inventories. Photogram. Engng., $19: 496-507$.

MUNSELL COLOR COMPANY INC. 1966 - Munsell Book of Color. Baltimore. Mariland, $160 \mathrm{p}$.

NORTHROP, E.K. \& JOHSON, E.W. 1970 - Forest Cover Type Identification. Photogram. Engng., 36:483-490.

PIMENTEL GOMES, F. 1970 - Curso de Estatística Experimental. São Paulo, Livraria Nobel. 430 p.

POPE, R.B. 1957 - The effect of Photo Scale on the Accuracy of Forestry Measurements. Photogram. Engng., 23 :869-873.

SCHREUDER, G.J. 1964 - Manual de Fotogrametria Forestal. Turrialba. Costa Rica, Instituto Interamericano de Ciências Agrícolas. $91 \mathrm{p}$.

SIMONTACCHI et alii 1955 - Considerations in the Preparation of Keys to Natural Vegetation. Photogram. Engng., $21: 582-587$.

SPURR, S.H. 1960 - Photogrametry and Photo Interpretation. N. York, Ronald Press. $472 \mathrm{p}$. 